\title{
One-sided Logic in Two-sided Markets
}

\author{
JULIAN WRIGHT* \\ Department of Economics, National University of Singapore
}

\begin{abstract}
In this paper, I consider eight basic fallacies that can arise from using conventional wisdom from one-sided markets in two-sided market settings. These fallacies are illustrated using statements made in the context of regulatory investigations into credit card schemes in Australia and the United Kingdom. I discuss how these fallacies may be reconciled by proper use of a two-sided market analysis, making reference to the relevant economics literature where applicable. The analysis is supported by observations on other two-sided markets.
\end{abstract}

\section{Introduction}

Recent regulatory investigations into debit and credit card schemes, such as the schemes offered by MasterCard and Visa, have paid little attention to the economics of two-sided markets. In this paper, I consider some basic fallacies that can arise when two-sided networks such as payment schemes are examined based on conventional wisdom rather than the logic of two-sided markets. These fallacies are illustrated using the reports of the Reserve Bank of Australia (RBA) and the Australian Competition and Consumer Commission (ACCC), which investigated the pricing and rules of the credit card schemes in Australia, and a report of the Office of Fair Trading (OFT), which investigated the pricing and rules of MasterCard in the United Kingdom.

Two-sided markets involve two distinct types of users, each of whom obtains value from interacting with users of the opposite type over a common platform. In these markets, platforms cater to both types of users in a way that allows them to influence the extent to which cross-user externalities are internalized. Rochet and Tirole (2004) offer a more precise characterisation.

Examples include academic journals which cater to readers and authors; airports which cater to airlines and passengers; auctions, B2B markets, car fairs, flea markets, shopping malls and trading posts which cater to buyers and sellers; dating agencies and nightclubs which cater to men and women; conferences which cater to speakers and to audiences; debit and credit card payment schemes which cater to cardholders and merchants; directory

* Department of Economics, Faculty of Arts and Social Sciences, National University of Singapore, AS2 Level 6, 1 Arts Link, Singapore 117570. E-mail: jwright@nus.edu.sg I appreciate helpful discussions on this topic with Henry Ergas of NECG, and comments on the paper by Mark Armstrong and Mark Donoghue. Any errors are my own. 
services such as Yellow Pages which cater to potential buyers and sellers; employment agencies which cater to employees and employers; hardware/software platforms such as video game platforms and computer operating systems which cater to users and content providers; expos and trade fairs which cater to potential buyers and firms promoting their goods; magazines, newspapers, public TV operators and web portals which cater to information/entertainment seekers and advertisers; quality assurance providers such as ETS which offer GRE and TOEFL exams to students and universities; real estate agencies which cater to home buyers and sellers, as well as to tenants and landlords; search engines which cater to searchers and websites; stock markets which cater to companies wishing to list and to investors/traders (through brokers); and text processors which cater to readers and writers. ${ }^{1}$ From this long list of two-sided markets, I focus on debit and credit card payment schemes since these have generated the greatest policy interest.

Some of the policy errors that are identified in this paper are not new. Evans (2003a) has noted some important antitrust issues raised by two-sided markets, and the need to pay attention to the economic logic of two-sided markets. For instance, he notes the need to consider both sides of the market when dealing with issues of market definition, market power and predation, a point that I will reiterate here. Rochet and Tirole (2003b), who argue against the current policy intervention in payment schemes, point out the perverse implications of cost-based regulation of individual prices in a range of other two-sided markets. The current paper contributes to the existing literature by identifying some new fallacies that have not previously been discussed, and by systematically illustrating these fallacies using the public statements of regulators.

The remainder of the article is divided into four sections. Section 2 details the eight fallacies using the simple example of nightclubs. Section 3 provides a brief overview of how payment schemes work and the economics of interchange fees for the reader who is not familiar with this industry. Based on the payment card industry, Section 4 shows that these fallacies are important in a policy context. It provides quotes from the public statements of regulators to illustrate the fallacies identified. The analysis reveals the use of conventional wisdom by regulators in the payments industry, rather than the logic of twosided markets. The recent economic theory of payment schemes and two-sided markets is also contrasted with the regulators' statements. Finally, Section 5 draws some overall lessons for other two-sided markets.

\section{The eight fallacies}

This section spells out eight fallacies that arise from using one-sided logic in two-sided markets. These fallacies are easiest to illustrate in the context of a very simple industry that of (heterosexual) nightclubs which seek to attract men and women who wish to interact. Although the nightclub industry may not be significant in a macro sense, there are several reasons why nightclubs are particularly instructive in illuminating these eight fallacies.

\footnotetext{
${ }^{1}$ Some of these examples have already been discussed previously in Armstrong (2002a), Evans (2003a), Evans (2003b), and Rochet and Tirole (2003a), while others are new. Some of the examples are in fact threesided markets - airports also serve retailers by providing retail space and stock markets also serve brokers by selling information services.
} 
The nightclub industry is a relatively straightforward one to describe. Unlike payment systems, there are no inter-party transfers, or scheme rules, that complicate a discussion of the observed outcomes. Individual nightclubs have low setup costs, and there is usually frequent entry and exit. At any point in time, there are typically numerous competing clubs. Many other examples of two-sided markets, including payment schemes, exhibit significant fixed and sunk costs so that normally only a few competing platforms will survive in a given market. This provides policymakers one avenue with which to explain the features of the industry they find troubling. For instance, if one side of the market is being charged more than its costs, this may be explained by a lack of platform competition. In the case of nightclubs, such explanations are easy to dismiss.

Nightclubs that men and women frequent can be considered as two-sided markets. ${ }^{2} \mathrm{Up}$ to a point, men prefer clubs patronized by more women, while women prefer clubs patronized by more men. Where it is legal, nightclubs often set different entry fees to men and women. ${ }^{3}$ These different charges will not generally be internalized by either party, even in the case where a man and a woman meet in the nightclub. With the possible exception of a couple going out together, when faced with two rival clubs (each with an equal number of men and women), men will prefer the club in which they pay less and women pay more (and likewise for women). Thus, the chance that two individuals will find a match in a particular club will depend not only on the sum of the charges to men and women, but also on the structure of the charges to the two types of users. To attract customers, clubs need to attract both men and women. By charging women less than men they can capture more patrons in total, if on average men care more about the number of women at the club than vice-versa. ${ }^{4}$ A lower price to women will attract more women, which is profitable since it increases the demand from men a lot. In the face of higher demand from men, the nightclub can raise its charge to men, increasing its profits.

\footnotetext{
${ }^{2}$ Cailluad and Jullien (2003) provide a formal analysis of such matching markets. They assume users do not care about the number of own types. One feature of nightclubs and many other matching models is that users may not only prefer more users of the opposite type, but to a certain extent they may prefer less users of the same type. To the extent this effect is stronger for men than for women, it provides another explanation for why men will be charged more, since each additional male patron provides a negative externality on other males in the club. The converse case is that of homosexual nightclubs, which involve only one type of user, and patrons care (positively) about the number of other patrons of the same type. Homosexual nightclubs are an example of a standard one-sided network.

${ }^{3}$ Some clubs have a lower cover charge or free entry for women, while others offer a ladies-night in which women pay nothing to enter the club on a given night of the week. In other cases, women can buy drinks at a fraction of the price that men must pay. Club Ing in Hong Kong has a ladies-night every Thursday offering free entry and drinks to women, while charging men US\$19 for entry which includes only one free drink. At Café Vogue in Johannesburg (South Africa) the cover charge is R50 for men, while women enter free before $11.30 \mathrm{pm}$. The nightclub at the Hard Rock Hotel in Las Vegas typically has a US\$20 cover charge for men, but is free for women. (Pricing data obtained from company websites on August $1^{\text {st }}$, 2003.) Evans (2003a) provides some further examples of differential pricing for nightclubs. In some jurisdictions, such pricing is considered sexual discrimination. See, for instance, Roth (2003). In the United Kingdom, the Equal Opportunities Commission explicitly bans such pricing in the Sex Discrimination Act 1975.

${ }^{4}$ This is consistent with the discussion of nightclubs in Roth (2003). Theoretical models also make such predictions. Armstrong (2002a) considers a model in which there are a fixed number of users of each type, each of whom values the number of users of the opposite type on the same platform, and who choose between participating in one of two differentiated platforms. In this model, competition results in prices being set higher to the type of user that cares more about the number of users of the opposite side (in this case, men).
} 
The cost of servicing an additional male and an additional female at a nightclub is likely to be quite similar. Thus, there would seem to be no cost basis for charging men more than women. Since, on average, nightclubs make little if any economic profit, the fact that they charge men more than women suggests women face a price below cost, and men face a price above cost. Based on the user-pays principle, one might conclude that such an outcome is inefficient. This leads to our first fallacy:

Fallacy 1: An efficient price structure should be set to reflect relative costs (user-pays).

An efficient structure of fees between those charged to men and those charged to women should not only take into account the relative costs of serving each type of user, but it should take into account the surplus that men enjoy when additional women are attracted (and vice-versa). If the surplus obtained by the male clientele from attracting an additional woman to the club is greater than vice-versa, then an efficient price structure will generally require that the price be lower for women than for men. Given these preferences, if prices are set equal, one might expect a club with at least as many men as women. Attracting an additional woman to the club raises the surplus to the existing men more than attracting an additional man to the club raises the surplus of the existing women. An efficient structure of fees will reflect this fact. In contrast, the principle of user-pays is not efficient in such a market.

A related fallacy arises from another basic principle of economics that can be misapplied to two-sided markets - the idea that competition should reduce prices to cost. Clearly, it is not true that competition, even perfect competition, will necessarily drive the price charged to each type of user to cost. As noted above, competition between nightclubs may result in men being charged above cost and women below cost. The observation that men are charged above cost does not, therefore, imply anything about the market power of the nightclub.

\section{Fallacy 2: A high price-cost margin indicates market power.}

Where men and women place a different value on matching with each other, a club that sets a symmetric fee structure will not generally attract as many users, and will not make as much profit, as a club that sets a differential fee structure. Competition will drive clubs to offer women cheaper entry fees, or other discounts, to attract the optimal balance of men and women at the club. The competitive structure of fees will generally not reflect costs. Moreover, the above-cost price to men can be permanently sustained above cost. This may simply indicate a difference in the surplus that men and women derive from being able to meet more members of the opposite sex.

Arguably, the ability of nightclubs to profitably set a price to men above marginal cost indicates they have some kind of market power over men (even though they make an offsetting loss on women). Thus, if one could define a separate market for men and women, then nightclubs which attract women might be found to have market power over men. ${ }^{5}$ The problem with such an approach is that the presence of market power does not

\footnotetext{
${ }^{5}$ Here it becomes important whether market power is defined as the ability to profitably sustain prices above marginal cost (in which case, by definition, each nightclub has market power on one side) versus whether market power is defined as the ability to profitably set prices above the competitive level (in which case, nightclubs may not have any market power).
} 
necessarily relate to any restriction of output, its ability to restrict competition, more general market failure, or even any deviation from the perfectly competitive benchmark for nightclubs. ${ }^{6}$ It is therefore not useful to follow such an approach. To draw sensible inferences about (harmful) market power through price-cost margins, loosely speaking one would need to demonstrate that the sum of fees to men and women could be profitably raised permanently above the costs of providing the service to both men and women.

An immediate corollary of the false identification of market power from a price being set above cost is the false identification of predation from a price being set below cost.

\section{Fallacy 3: A price below marginal cost indicates predation.}

As noted in footnote 3 , sometimes the cover charge women face is permanently set at zero, which is clearly below marginal cost. However, far from representing predatory pricing, below-cost prices may be used to generate greater surplus by attracting those users (women) that provide the greatest benefits to the network of other users (men). While such a price structure may represent an attempt by a firm to attract greater market share, since prices can be profitably retained below cost, it would make no sense to think of this as predation. $^{7}$

The fourth fallacy considered is the claim that greater competition will necessarily result in a more efficient structure of prices. While this may be true in some settings, it need not be the case.

Fallacy 4: An increase in competition necessarily results in a more efficient structure of prices.

Consider the case of a nightclub. A single (monopoly) nightclub will still have an incentive to set a lower entry fee for women compared to men. Such a nightclub can capture the greater willingness of men to pay, when it attracts additional women. Thus, there is no $a$ priori reason to think that in general, greater competition will result in a more efficient structure of prices. While competition will lower the overall level of prices charged to men and women, competition could result in a structure of prices (the relative level of entry fees charged to men and women) that is closer to, or further away, from the efficient structure. ${ }^{8}$

\footnotetext{
${ }^{6}$ In other words, the finding of market power on one side provides no reason to worry about the behaviour of the nightclub, and so there should be no consequences to such a finding. An example where the ability of platforms to control access to one side of the market does result in the platforms setting an inefficiently high price to the other side is that of fixed-to-mobile calls under caller-pays regimes, a case which has been called a competitive bottleneck. See Armstrong (2002b) and Wright (2002) for a formal analysis. In this case, a bottleneck over terminating calls to their own mobile subscribers results in a significant distortion in the structure of fees charged for fixed-to-mobile calls and mobile subscribers. Note however, competition between mobile platforms does not remove this market failure (it just shifts the rents to mobile subscribers), so that even in this case, a finding of market power on one side would not have the usual implications. This suggests it is more useful to define market power looking at both sides of the market together, and to investigate any serious distortions in the structure of prices arising from a competitive bottleneck as a separate matter.

${ }^{7}$ To draw inferences about predation through prices and costs, one would again need to look at the sum of fees charged to men and women and relate this to the costs of providing the service to both types of users.

${ }^{8}$ Rochet and Tirole (2003a) show that for the case with linear demands and in which sellers do not behave strategically, the structure of prices in a generic two-sided market is the same for the case of a monopoly platform and competing platforms, where platforms only charge for transactions.
} 
Thus, while in normal markets antitrust is designed to protect the workings of competition (and so desirable outcomes), it is not clear that competition will result in (or is needed for) efficient price structures.

A related fallacy arises from assuming that greater competition will necessarily result in a more balanced price structure. While competition will generally lower the total (or average) level of prices charged to men and women, it will not necessarily lower the price charged to men relative to women.

Fallacy 5: An increase in competition necessarily results in a more balanced price structure.

Again, this is a case of anything-is-possible. Competition could lead to a more balanced price structure, but it could just as well lead to a greater imbalance in prices. Which outcome is more likely to arise will likely depend on the specifications of demand and how competition interacts with the demand of each type of user. For instance, if men tend to be loyal to particular bars, then greater competition might be reflected in a lowering of the price on the more competitive female side (resulting in even more imbalanced prices). On the other hand, if women tend to go to several bars during the same evening, then greater competition between bars could manifest itself in lower prices to men who only need to be attracted to one bar given that women will frequent many.

One argument sometimes given against the asymmetric pricing structures observed on two-sided markets is that while they may be justified in the start-up phase of a network, they are no longer justified once the network is established. This type of logic gives rise to the sixth logical error considered.

Fallacy 6: In mature markets (or networks), price structures that do not reflect costs are no longer justified.

Setting prices below cost for one type of user (and above cost for the other) may be justified in the start-up phase of a network as a way to overcome a chicken-and-egg type problem. For a nightclub, the problem would be how to attract the patronage of men given the nightclub attracts no women, and how to attract the patronage of women given the nightclub attracts no men. Sometimes, this kind of chicken-and-egg problem can be resolved by providing free entry of one type, thereby attracting the other. ${ }^{9}$ However, even once a nightclub has established a base of regular clientele, it will still be beneficial for the nightclub (and for overall efficiency) if lower prices are set to women and higher prices are set to men if an additional female provides greater surplus to male patrons than vice-versa. Thus, a chicken-and-egg problem is not necessary to explain why in two-sided markets prices may efficiently deviate from cost - if it was, nightclubs would not offer discounted entry to women once they are well established.

Another fallacy arises if the asymmetric pricing structure that platforms set to promote demand on their networks is misinterpreted as an economic cross-subsidy. A cross-subsidy can arise in economics if one group of users contributes less than their incremental cost (the additional cost of providing the services the group consumes, over and above the cost

\footnotetext{
${ }^{9}$ See for instance the conquer-and-divide strategy of an entrant described in Caillaud and Jullien (2003). In the case of nightclubs, the chicken-and-egg problem may be solved by some opening promotion that attracts both types of users simultaneously (say, to get prizes, cheap drinks, etc).
} 
of providing the services to others). ${ }^{10}$ Assuming the firm at least breaks even, this implies some other group of users contributes more than their stand-alone cost (the total cost of providing the group with the service they consume), and so is cross-subsidizing the former group.

Fallacy 7: Where one side of a two-sided market receives services below marginal cost, it must be receiving a cross-subsidy from users on the other side.

If women are given free entry to the nightclub, this suggests that men are paying more than the total costs of providing the night club services that they consume, while women are not paying even the incremental costs of providing the services they consume. ${ }^{11}$ The economic cross-subsidy in this case would seem to run from men to women. The problem with this logic, however, is that it ignores the fact that the service that is being provided to each type of user depends on whether the service is also provided to the other type of user. The removal of the service to either men or women may result in a loss of all revenues to the nightclub given that without attracting both types of users, nightclubs will not attract either. In this case, the additional revenue obtained from offering the service to women in addition to men is actually the total revenue obtained by the club. This means the revenue generated from each type of user will more than cover their incremental costs, and hence there cannot be any cross-subsidy.

Another way of demonstrating the lack of a cross-subsidy is to note that if there was a cross-subsidy from men to women, then it would follow that men would necessarily be better off if women were banned from the nightclub. It would also imply a rival nightclub that just catered to men could set up and profitably undercut the original nightclub. Clearly, this is not the case in this setting. With no female patrons, such a nightclub would only be able to charge a fraction of the price to men (if anything). Such a ban would not be profitable. In some cases, men may even be worse off if the nightclub charged them less and women more. Although such a change in pricing would provide men with a direct benefit (a lower cover charge), if the change results in reduced patronage by women, it could ultimately make them worse off. This is why a nightclub that offers ladies-nights but that has higher charges to men does not necessarily attract fewer men.

The final fallacy I discuss in this paper is the idea that regulating the structure of prices of some platforms in two-sided markets is competitively neutral. A regulation of one firm (or set of firms) is competitively neutral if it does not provide any competitive advantage for rival unregulated firms. One set of firms (A) will obtain a competitive advantage over another set (B) as a result of regulations when the regulations make $\mathrm{A}$ better able to maintain and win customers relative to B. Price regulation in normal industries may be competitively neutral if the market is sufficiently competitive. For instance, suppose regulations force B to lower its retail prices. Provided the retail price of B is not lowered so much that it can no longer cover its costs, this does not enable A to better maintain and win customers relative to B. In fact, to maintain its current number of customers, A will have to lower its retail prices by roughly the same amount as B. In this case, the regulation will not

\footnotetext{
${ }^{10}$ See Faulhaber (1975).

${ }^{11}$ For this discussion, I ignore the possibility that nightclubs make money on the drinks sold to females, which could mean that even if women are given free entry, they may still pay more than their incremental cost.
} 
provide any competitive advantage to A. This logic, however, does not apply to the individual prices of a two-sided market.

Fallacy 8: Regulating prices set by a platform in a two-sided market is competitively neutral.

Forcing a platform to set a lower price on one side of its business may not result in its rival(s) following suit. The unregulated platform will not want to match a suboptimal structure of prices imposed on the regulated platform. This may provide the unregulated platform(s) with a competitive advantage, even though in a one-sided context regulating lower prices for one firm does not generally advantage their unregulated rival(s).

Suppose a certain group of nightclubs is banned from running ladies-nights, perhaps on the grounds these discriminate against men. ${ }^{12}$ Will the remaining bars still want to run ladies-nights or will they be driven to charge men the lower amounts now charged by regulated bars? For the very reason ladies-nights are a way to attract more business, the remaining bars may still want to charge women less and men more. Even though regulated bars will charge men less, many men may still prefer to pay more to go to the bars which advertize the ladies-nights, since this gives them a better chance to meet women. Overall, the unregulated firms may increase their market share and profits as a result of the regulation. The logic of the argument does not depend on the market share of the bars that are regulated versus those that remain unregulated, or on the extent of competition between bars.

\section{A brief overview of card schemes}

While the example of nightclubs was convenient to illustrate how conventional wisdom can go astray when applied to two-sided markets, the example of card schemes more usefully illustrates the relevance of these fallacies in a policy context, as well as better links them to the theoretical literature on two-sided markets. For this reason, this section briefly reviews the workings of debit and credit card schemes, such as those offered by American Express, MasterCard and Visa. ${ }^{13}$ These schemes each create a payment instrument which consumers can use for the deferred payment of goods and services purchased from merchants, and which merchants can use to receive guaranteed payment for goods and services sold to consumers.

To understand the economics of card schemes, it is simplest to start with a discussion of proprietary card schemes, such as those offered by American Express and Discover. Such schemes directly attract cardholders who wish to use cards to pay at merchants, and merchants who wish to accept such payments from cardholders. A central decision made by the card scheme is how much to charge cardholders versus how much to charge merchants. If one considers only the payment services offered by card schemes, such schemes typically recover most of their revenue from merchants. They do this through

\footnotetext{
${ }^{12}$ See Roth (2003) for a discussion of the views of some San Diego nightclubs on being banned from running ladies-nights. To the extent there are other nightspots which do not rely on ladies-nights to draw in patrons, the ban could shift business away from those that do.

${ }^{13}$ Useful surveys of payment schemes include Evans and Schamlensee (1999), Chang and Evans (2000), Chakravorti (2003) and Chakravorti and Shah (2003).
} 
merchant fees, fees that are obtained as a percentage of the value of each card transaction. For instance, Evans (2003a) reports that American Express earned 82 percent of its revenues from the merchant side of the business in 2001. In contrast, consumers are only sometimes charged annual fees, and often are given rebates such as frequent flyer miles based on the value of their card transactions. For consumers who do not roll over (much) credit card debt, credit cards may cost them nothing to use, or in the case of pure transactors, may provide a net financial benefit.

Since the fees charged to merchants are not typically passed on by merchants to their customers who pay by cards, the structure of pricing set by payment networks clearly matters. ${ }^{14}$ As card schemes charge less to cardholders and more to merchants, there will be increased card holding, card usage, and fewer merchants willing to accept cards. By setting the right structure of prices between those charged to cardholders and those charged to merchants, a card scheme can achieve its preferred balance between getting people to hold and use cards, and having merchants accept cards. If the card scheme sets its structure of prices to maximize its profit, it will generally set a structure that achieves a high number of card transactions. At the same time, if it can, a proprietary scheme will raise the overall level of fees to restrict card transactions and increase profits.

A card association such as MasterCard or Visa faces the same problem as a proprietary scheme of achieving the right balance between cardholder and merchant fees. However, card associations differ from proprietary schemes since they do not set these fees directly. Instead, it is the members of a card association which set these fees. In a card association, member banks and other financial institutions deal directly with cardholders (these institutions are called "issuers") and with merchants (these institutions are called "acquirers"). ${ }^{15}$ While the scheme administrator authorises, clears and settles transactions between issuers and acquirers, it does not directly set retail prices such as cardholder annual fees or merchant fees. Instead, to achieve its desired structure of prices between those charged to cardholders and those charged to merchants, a card association sets what is known as an "interchange fee".

An interchange fee is a fee paid from the merchants' bank (the acquirer) to the cardholders' bank (the issuer) whenever the cardholder uses his card to make a purchase at a merchant. From the point of view of acquirers, the interchange fee is a cost of providing their services to merchants. An increase in the interchange fee will lead to an increase in acquirers' costs for every card transaction they process. Acquirers will therefore respond to an increase in the interchange fee by increasing their merchant fees. This is true regardless of whether there is a single acquirer, or if there is strong competition between different acquirers. Similarly, from the point of view of issuers, the interchange fee is a rebate obtained for providing their services to cardholders (a payment that they receive). An increase in the interchange fee will mean an increase in the rebate issuers' receive for every card transaction they process. Issuers will therefore respond to an increase in the interchange fee by increasing their rebates to cardholders and/or decreasing their card fees,

\footnotetext{
${ }^{14}$ In fact, merchants typically set uniform prices regardless of the type of payment. This observation could reflect the no-surcharge rules that card associations have adopted to prevent merchants from charging more to consumers for purchases made with cards. Evidence from the Netherlands and Sweden suggests even without these rules, most merchants do not set differential prices based on the means of payment (see Wright, 2004).

${ }^{15}$ Card associations are sometimes called four-party payment schemes in reference to the four main parties involved in the scheme aside from the scheme administrator. These parties are the issuer, the acquirer, the cardholder, and the merchant.
} 
so as to encourage more card transactions. This is true regardless of whether there is a single issuer, or if there is strong competition between different issuers. ${ }^{16}$

The net effect of an increase in a card association's interchange fee will therefore be to increase its acquirers' merchant fees and to decrease its issuers' card fees. To the extent that the increase in merchant fees exactly equals the decrease in card fees, the only effect of an increase in the interchange fee will be a change in its fee structure with no change in the overall level of the issuers' and acquirers' fees. To the extent that the increase in merchant fees does not match the decrease in card fees, changing the interchange fee will change the fee structure, and, at the same time, change the overall level of the issuers' and acquirers' fees.

In either case, the interchange fee is the key instrument the card association can use to achieve a particular structure of cardholder and merchant prices. For instance, if MasterCard and its members want to achieve high merchant fees and low card fees, they will require a relatively high interchange fee. If MasterCard and its members want to achieve high card fees and low merchant fees, they will require a relatively low interchange fee. If the interchange fee is set at zero, then competitive issuers and competitive acquirers will each set their prices at the respective costs of dealing with cardholders and merchants. In this sense, the interchange fee is the instrument that card associations must rely on if they are to set a structure of prices which leads to the right balance of cardholder and merchant demand. ${ }^{17}$

\section{$4 \quad$ Evidence from policy statements and the academic literature}

In this section, the fallacies described in Section 2 will be illustrated using the reports of the Reserve Bank of Australia (RBA) and the Australian Competition and Consumer Commission (ACCC) ${ }^{18}$, which investigated the pricing and rules of the credit card schemes in Australia, and a report of the Office of Fair Trading (OFT) ${ }^{19}$, which investigated the pricing and rules of MasterCard in the United Kingdom. Where possible, the fallacies will also be related to the academic literature that has been directed at understanding the economics of payment schemes.

Regulators the world over seem to have an overriding desire to set prices based on costs. In network settings, in which cross-user externalities are important, the efficiency implications of cost-based prices can be undesirable. This is likely to be the case in many two-sided markets. Fallacy 1 in Section 2 noted an efficient price structure in a two-sided network need not be set to reflect relative costs. User-pays may not pay! Despite this,

\footnotetext{
${ }^{16}$ Since an increase in rebates for cardholders will have similar effects on consumers' demand as a decrease in card fees, for simplicity I will refer to both as simply a decrease in card fees.

${ }^{17}$ In contrast, without separate issuers and acquirers, proprietary schemes set their preferred structure of prices directly.

${ }^{18}$ Three documents will be used. These are: Reserve Bank of Australia and Australian Competition and Consumer Commission, Debit and Credit Card Schemes in Australia: A Study of Interchange Fees and Access, October 2000 (hereafter the "Joint Study"); Reserve Bank of Australia, Reform of Credit Card Schemes in Australia - I - A Consultation Document, December 2001 (hereafter the "RBA Consultation Document"); and Reserve Bank of Australia, Reform of Credit Card Schemes in Australia - IV - Final Reports and Regulation Impact Statement, August 2002 (hereafter the "RBA Final Report").

${ }^{19}$ Office of Fair Trading, MasterCard Interchange Fees - Preliminary Conclusions, February 2003 (hereafter the "OFT Preliminary Conclusions").
} 
regulators of payment schemes have called for interchange fees, which determine the structure of prices charged to cardholders versus merchants, to be cost-based. For instance, the OFT states:

\begin{abstract}
"The OFT's preliminary conclusion is that MasterCard has not justified the level at which it has set its MIF. The OFT accepts that the MIF could be justified if it was set a level which covered the costs of the payment system services which issuers provide to merchant acquirers and retailers. These payment system costs would include the costs of processing transactions, for example. However, the MasterCard MIF has been set at a level much higher than these costs." (OFT Preliminary Conclusions at 3.12$)^{20}$
\end{abstract}

Similarly, the ACCC and RBA state:

\begin{abstract}
"Nonetheless, there are two broad tests which any interchange fee regime should be expected to meet if it is to contribute to efficient resource allocation. Interchange fees should: - not overcompensate financial institutions for the costs that they incur; and • be subject to regular review as costs and other conditions in the relevant payment network change ... Credit card interchange fees are significantly above levels suggested by cost-based methodologies." (Joint Study, p.73)

"Interchange fees are higher than can be justified by costs, and scheme members lack clear incentives to bring these fees into line with costs." (RBA Consultation Document, p.6)
\end{abstract}

The RBA goes on to suggest that user-pays is the correct principle for setting prices for credit card services, stating:

\begin{abstract}
"The reforms will have a direct impact on credit cardholders and are likely to result in some repricing of credit card payment services, but such a move towards "user pays" is the means by which the price mechanism directs users of the payments system towards the most efficient choice of payment instruments." (RBA Final Report, p.34)
\end{abstract}

Contrary to these statements, adopting a price structure that reflects the costs of serving each type of user (user-pays) would only be efficient by chance. The same can be said of an interchange fee that is set equal to the cost of issuing (or any other measure of cost). The idea of a cost-based interchange fee is based on treating issuers as providing a service only to merchants. Once account is taken of the fact that card schemes also provide a service to cardholders, and that both types of users get benefits from a card transaction only if both want to use them, then there is nothing particularly desirable about cost-based interchange fees (Baxter, 1983).

Nor should prices to cardholders and merchants be based solely on the costs that these users impose. With competitive issuing and acquiring, this would correspond to setting interchange fees at zero so that each issuer recovers its costs directly from cardholders, and each acquirer recovers its costs directly from merchants. When cardholders use cards for transactions, merchants will obtain certain benefits. When merchants accept cards for transactions, cardholders will obtain certain benefits. What matters for efficient card usage is that consumers use cards whenever the sum of their own and the merchant's benefits exceed the sum of the associated issuer and acquirer costs. Since issuers will pass on their own costs to cardholders, and since cardholders already take into account their own

\footnotetext{
${ }^{20}$ Note the OFT use the acronym "MIF" to refer to the (multilateral) interchange fee.
} 
transactional benefits, to achieve this requires cardholders (and therefore issuers) receive a payment from acquirers equal to the merchants' transactional benefits less the acquirers' costs. This is exactly the idea of the Baxter interchange fee. This ensures consumers take into account their own and their merchant's benefits, and face both the issuing and acquiring costs. ${ }^{21}$

There seems to be an academic consensus that there is no basis for setting interchange fees to zero or equal to cost. For instance, Katz states:

"Summarizing the findings on socially optimal interchange rates, there are situations in which it is optimal to use interchange fees to rebalance the costs and benefits enjoyed by the two sides of a card-based transaction. The socially optimal fee level depends on the nature of merchant, issuer, and acquirer competition, as well as consumer characteristics. As a general matter, when no-surcharge rules are in effect, there is little reason to believe that it is optimal to set the interchange fee equal to either an issuer's marginal cost of a card transaction or zero." (Katz, 2001, p. 29)

Rochet and Tirole state:

"In agreement with Katz (2001), we in particular explain why there is no economic rationale for cost-based regulation of IFs" (Rochet and Tirole, 2003b, p. 69) ${ }^{22}$

and Hunt states:

\begin{abstract}
"From the standpoint of policy, the literature suggests three important conclusions. First, a variety of factors may result in a privately determined interchange fee that diverges from the socially optimal fee, resulting in payment networks that are either too large or too small. Second, a zero interchange fee is generally not socially optimal. And third, an interchange fee based purely on costs, ignoring the effect of changes in prices on consumers' and merchants' demand for payment services, is generally not socially optimal." (Hunt, 2003, p. 88)
\end{abstract}

The second fallacy considered in Section 2 was the use of high price-cost margins on one side of the market as an indicator of market power. Often one might try to infer market power from the fact a firm can profitably sustain its price (significantly) above cost. However, even in a perfectly competitive two-sided market, it is normal for the price on one side of the market to be above cost and the price on the other side to be below cost. Such a price structure does not reflect any market power. Rather, this might reflect the need to encourage demand by one type of user rather than another, so as to increase the total demand for the service. Thus, pricing below cost to cardholders and above cost to merchants may be a way of boosting total demand for card transactions, even amongst

\footnotetext{
${ }^{21}$ Loosely speaking, this is also the socially optimal interchange fee that is implied by the analysis of Rochet and Tirole (2002), Wright (2003a) and Wright (2004). In these analyses, competition between merchants is taken into account, which implies merchants will already internalize the effect of card acceptance on the benefits of their customers who use cards. It remains for consumers to face the right price signal. Provided it is consistent with merchants' accepting cards, the right price signal is given at the Baxter interchange fee (or its generalization in Wright, 2004 to the case where different merchants have different benefits of accepting cards). The Baxter interchange fee requires some adjustments in the case issuers are not perfectly competitive, since then issuers may not fully pass through the interchange revenue as a rebate to consumers, meaning a higher interchange fee may be needed in order to ensure consumers face the full costs and benefits of their card usage (Rochet and Tirole, 2002).

${ }^{22}$ The authors use "IFs" to mean "Interchange Fees".
} 
highly competitive card schemes. One cannot sensibly determine that a card scheme has market power by finding that merchants pay fees that are above the associated cost of acquiring.

As evidence that regulators are susceptible to this fallacy, note the statements of the ACCC and RBA in this regard:

"Competitive pressures in card payment networks in Australia have not been sufficiently strong to bring interchange fees into line with costs." (Joint Study, p.iv)

Summarizing the findings of the earlier Joint Study, the RBA states:

\begin{abstract}
"It also found that the fees are higher than the costs incurred by issuers in providing credit card payment services to merchants and that - because of barriers to entry to the schemes - competition does not seem to be bringing these fees into line with costs." (RBA Consultation Document, p.16)
\end{abstract}

Much of the academic literature on card schemes has been based on the assumption of just a single card scheme. ${ }^{23}$ Yet, this literature predicts the monopoly scheme will set an interchange fee (and a resulting structure of prices) that need not be inefficient. Even a monopoly card scheme does not have an obvious incentive to distort the structure of prices, unless setting a particular structure of prices can be used to raise its overall level of prices (Wright, 2004). This is unlikely to be possible if there is strong competition between issuers and between acquirers. Even where there is a single issuer and a single acquirer, Schmalensee (2002) shows a monopoly scheme will set the efficient interchange fee in the case where demands are linear and merchants do not behave strategically.

While policymakers have made claims about card schemes using market power to set above-cost merchant fees, they have ignored the equally troubling claim on the other side of the market - that the below-cost prices set to cardholders indicate predatory pricing (Fallacy 3). As noted in Section 2, this fallacy is particularly easy to resolve. Since fees to cardholders may be profitably retained below costs, such pricing cannot represent a case of predation.

The fourth fallacy considered in Section 2 was that greater competition between platforms in two-sided markets will result in a more efficient structure of prices. Just as conventional wisdom holds that cost-based prices are efficient, so it implies that greater competition will result in prices moving closer to cost and efficiency improving. While such statements may apply to the overall level of prices charged to cardholders and merchants, they do not apply to the structure of prices charged to the two types of users. In fact, it could be that strong platform competition leads to a more distorted structure of prices, with too much being charged to one side relative to the other. ${ }^{24}$ It is also possible that a monopolist will set the same structure of prices as set by competing platforms. ${ }^{25}$

\footnotetext{
${ }^{23}$ See for instance the models of Baxter (1983), Gans and King (2003), Rochet and Tirole (2002), Schmalensee (2002), Schwartz and Vincent (2001), Wright (2003b) and Wright (2004).

${ }^{24}$ Guthrie and Wright (2003) show that price competition between two identical card associations can lead to the platforms setting interchange fees too low (providing some consumers want to hold both cards). The equilibrium is characterized by both platforms setting a fee structure that maximizes the surplus merchants obtain from accepting cards. If either scheme tries to set a higher interchange fee, merchants will reject the card, knowing that consumers will hold and use the other card, which they prefer to accept. The resulting interchange fee is too low, since it is determined only by the interests of merchants. On the other hand, if all
} 
In contrast to the logic of two-sided markets, the regulators of payment schemes have stuck with conventional wisdom. The OFT claims that the collectively set interchange fee:

"removes incentives for the parties to enter into bilateral agreements, which can be expected to mean that there will be little or no competition between them over the level of the interchange fee." (OFT Preliminary Conclusions at 3.3)

The OFT goes on to claim that the collectively set interchange fee:

"leads to higher merchant service fees which will be passed on to consumers through higher retail prices.” (OFT Preliminary Conclusions at 3.4)

The implicit assumption is that more competition over the interchange fees, in this case by way of bilateral agreements between individual issuers and acquirers, will be desirable. ${ }^{26}$ The RBA is more explicit, stating:

"Competition between payment instruments is critical to the claim that interchange fees cannot rise above "efficient" levels because such competition will keep them in check." (RBA Consultation Document, p.37)

"In Australia, credit card interchange fees are not determined by a competitive market. While it is possible that a collective process may lead to interchange fees being set at an efficient level, the conditions under which this is likely to occur in practice - strong competition between credit card schemes, strong competition between credit cards and other payment instruments, and a balance of issuing and acquiring interests in the fee-setting process - do not prevail in Australia. ... Where the competitive environment is not robust, the risk is that collectively set interchange fees can be above an efficient level ..." (RBA Final Report, p.8)

"Until there is more robust competition, the circumstances under which credit card interchange fees are collectively set in Australia create the risk that interchange fees would not be set at an efficient level, resulting in distorted price signals to cardholders and merchants." (RBA Final Report, p.33)

These statements also suggest that the RBA holds the view that greater competition between schemes will result in more symmetric prices (Fallacy 5). This follows from the RBA's argument (given above) that the unregulated interchange fees in Australia were above the efficient level, and that the culprit was a lack of competition between payment schemes. The implication is that greater competition will decrease interchange fees, thereby decreasing merchant fees and increasing card fees, resulting in a more balanced set of fees. However, as the discussion of Fallacy 5 makes clear, there is no general principle in two-sided markets that ensures greater platform competition will result in more balanced fees. ${ }^{27}$ In the context of interchange fees, this implies that greater scheme competition

consumers only hold one card, competing schemes will set interchange fees too high in an attempt to be the card that is held, and therefore used, exclusively.

${ }^{25}$ Rochet and Tirole (2003a) show this is the case in a model of competing platforms in which demands are linear and sellers do not behave strategically.

${ }^{26}$ Small and Wright (2001) show that allowing interchange fees to be set bilaterally by competing issuers and acquirers can lead to an escalation of interchange fees above the level set collectively.

${ }^{27}$ Both Guthrie and Wright (2003) and Rochet and Tirole (2003a) find cases where competing schemes set the same structure of fees as a single scheme. Guthrie and Wright also find cases in which competition results in a more symmetric fee structure and a case in which competition results in a more asymmetric fee structure (see footnote 24). 
cannot guarantee lower interchange fees, and therefore merchant fees. Despite this, the RBA state:

"In the absence of regulatory action by the Reserve Bank, merchants would continue to pay a higher price for credit card acquiring services than if more competitive conditions prevailed." (RBA, Final Report, p.16)

Fallacy 6 states that in mature networks, there is no need for prices to deviate from costs as network effects will no longer be so critical. In the context of payment schemes, the implication is that once the networks are well established, interchange fees can be set at zero. In this case, competitive issuers will simply pass on their costs to cardholders, and competitive acquirers will pass on their costs to merchants. While policymakers have generally stopped short of suggesting that interchange fees for credit card networks should be set to zero ${ }^{28}$, they have suggested network effects no longer provide a justification for prices or interchange fees deviating from costs since the networks will be viable with costbased fees. For instance, the ACCC and the RBA state:

\begin{abstract}
"The intent of an interchange fee is to ensure that network benefits are taken into account by overriding the usual market mechanisms under which buyers and sellers compare private costs and benefits. While this may be justified in the early stages of development of a payment network, the weakening of normal price signals in a mature network can lead to higher interchange fees than are necessary to establish and maintain the viability of the network." (Joint Study, p.28)

"Interchange fees may have played an important part in the development of these networks, but by their nature they have done so by reducing the potency of the normal market mechanisms which determine consumer choice and resource allocation. While a pricing system based on interchange fees still seems to be the most practical arrangement for the credit card network, the levels of interchange fees are high relative to costs and fees of this magnitude are not essential to the continued viability of this network." (Joint Study, p. 80)
\end{abstract}

The argument given seems to be that for the initial development of payment networks, interchange fees were needed to ensure the viability of the schemes, but they are no longer needed since these networks have obtained critical mass. It is true that provided there is not a dramatic loss of business to proprietary schemes, the existing payment schemes would still be viable with interchange fees set at zero (individual issuers and acquirers would adjust their prices accordingly to retain profitability). However, it is not clear why scheme viability is the relevant criterion for setting interchange fees. One does not need a chickenand-egg problem to justify setting interchange fees. Instead, since any card transaction involves two parties, there is a role for interchange fees to ensure consumers face the joint costs and benefits of their decisions. This is just as true in a mature network as it is in a start-up network. ${ }^{29}$

\footnotetext{
${ }^{28}$ The ACCC and RBA have proposed zero interchange fees for the on-line debit card system (EFTPOS) in Australia (Joint Study, pp. 68-69).

${ }^{29}$ It is notable that in the existing payment schemes literature, the role of the interchange fee is derived under the assumption of mature networks. Thus, for instance, Baxter's socially optimal interchange fee holds for a mature network. Self-fulfilling equilibria in which a scheme will not attract any users because none are expected to join are not considered. Caillaud and Jullien (2003) study such a chicken-and-egg problem in the context of a generic matching market, and show that the structure of fees can sometimes be used by an entrant firm to overcome the chicken-and-egg problem.
} 
One interpretation of the policymakers' statements is that they have mixed up externalities arising from network membership with those arising from usage. Their argument could be interpreted as saying that in mature payment networks, merchants will accept cards regardless of the pricing to cardholders, and so there is no justification for a subsidy to card holding (or issuing). However, an important impact of interchange fees is on consumers' usage decisions. As explained above, the interchange fee should be set so consumers internalise the joint costs and benefits of their usage decision. This fact is not diminished by the maturity of the network. This is not to say that maturity will not impact on the choice of interchange fees. As networks mature, the nature of the costs and benefits of card usage will likely change, and so might the optimal interchange fee.

Another error made by the policymakers is to confuse the use of transfers between the different sides of a two-sided market, and the concept of a cross-subsidy. ${ }^{30}$ The idea is that consumers who pay by credit card but who pay off their balance in full at the end of the month pay nothing towards the costs of the services they enjoy, and so they must enjoy a cross-subsidy from some other users. Since merchants cover these costs through merchant fees, and since merchants are funded by all their customers, the cross-subsidy must be between those paying by alternative means and those paying by credit cards ${ }^{31}$ In particular, the ACCC and RBA state:

\begin{abstract}
"A greater contribution by cardholders to the costs of using a credit card would provide scope to lower interchange fees, merchant service fees and prices of goods and services. The present fees charged to merchants are ultimately passed on to all consumers - not just those using credit cards in the form of higher prices of goods and services. In effect, credit card users are being crosssubsidised by other customers. One way of ensuring that cardholders bear more of the costs is through increases in direct charges by card issuers." (Joint Study, p.52)

"To the extent that credit card payments are more costly for merchants than some other payment instruments, displacement of these instruments by credit cards raises merchants costs. These costs are ultimately passed on to all consumers in the form of higher prices, giving rise to the crosssubsidisation of credit card users mentioned above." (Joint Study, p.54)

"Cardholders who use credit cards purely as a payment instrument contribute least to the cost of credit card schemes and, in some cases, are effectively paid to use credit cards. A greater contribution from such cardholders would reduce the subsidy they receive from other consumers." (Joint Study, p. 59)
\end{abstract}

However, contrary to the suggestion of the ACCC and RBA, there is no cross-subsidy in this case. To see this most simply, consider the case of an American Express charge card, which merchants pay for through merchant fees, and which consumers pay nothing to use. Suppose some consumers use this card, while all other consumers use cash (which is assumed to be costless). Suppose, further, that the price of goods sold by merchants is increased to cover the merchant fee. Even under these somewhat extreme assumptions, users of American Express charge cards do not enjoy a cross-subsidy from cash-users. If they did, then a merchant would be better off if the consumers who pay by American Express charge cards were banned from using the card for purchases at the merchant's

\footnotetext{
${ }^{30}$ This is Fallacy 7 in Section 2.

${ }^{31}$ Since in practice consumers pay by different means at different times, since most consumers use credit card debt at some point in time, and since some other instruments may be just as expensive for merchants to accept as credit cards, the factual basis for claims about transfers between different groups of users is not in fact obvious.
} 
store. One can safely assume this is not the case, for if it were, it would contradict the fact the merchant voluntarily chooses to accept cards, presumably to increase overall profits.

Another test of whether a cross-subsidy exists is whether card paying customers increase American Express' revenue by less than the additional costs they give rise to. Again, this cannot be the case. Without attracting these cardholders, American Express would not attract any merchant fees, and so it cannot be better off by excluding such users. ${ }^{32}$

The final fallacy considered in Section 2 was the claim that the regulation of prices in two-sided markets is competitively neutral. This is a matter of particular importance in the context of regulating interchange fees. Since the interchange fee is the primary instrument a card association can use to influence the structure of prices to cardholders versus merchants, regulating interchange fees is akin to fixing this structure of prices within card associations. This provides proprietary schemes, which do not require an interchange fee to achieve their desired price structure, with a potential competitive advantage. ${ }^{33}$

The RBA dismisses this view when they state:

"The Reserve Bank's proposed standards and access regime will apply to the three designated credit card schemes, Bankcard, MasterCard and Visa. The "three party" card schemes - American Express and Diners Club - do not have collectively set interchange fees nor restrictions on entry enforced by existing members, and the Reserve Bank saw no case on public interest grounds to designate these schemes to deal with these issues." (RBA Consultation Document, p.1x)

"Submissions have also argued that a standard for interchange fees in the designated credit card schemes will prevent these schemes from being able to compete effectively with the three party card schemes. This raises the question of the nature of competition between four and three party card schemes in Australia. On the basis of network size, the four party credit card schemes would appear to have a dominant market position compared with the smaller three party card schemes." (RBA Consultation Document, p.118)

"If a standard for interchange fees resulted in lower merchant service fees in the designated credit card schemes, normal competitive processes would ensure that competitors would have to react." (RBA Consultation Document, p.119)

The RBA argues that because merchant fees will decrease (as a result of lower interchange fees) in card associations, competition will cause proprietary schemes to also decrease their merchant fees. In the RBA's view, interchange fee regulation will be competitively neutral. However, this view of competition is one-sided. Competition does not just lower prices on one side of the market. Rather, competition between schemes takes place with respect to both sides of the market simultaneously. If card associations are prevented from setting a structure of prices that maximizes the value of their schemes to their customers (both cardholders and merchants), the demand for their card transactions will fall relative to proprietary schemes.

\footnotetext{
${ }^{32}$ Even if non-card users are worse off as a result of consumers using credit cards, this does not constitute a cross-subsidy, but rather reflects the fact that the existence of credit cards may have distributional effects. ${ }^{33}$ The lack of an explicit interchange fee in proprietary schemes simply reflects these schemes' different organizational form. Despite the lack of an explicit interchange fee, proprietary schemes still care about getting the right structure of fees between cardholders and merchants. They still charge merchants more than consumers for the payment service associated with their cards. This, in turn, enables them to offer more value to their customers and to increase the use of their cards.
} 
Guthrie and Wright (2003) demonstrate this result formally in a model with perfect competition between card schemes. They show that if one card association has its interchange fee regulated below the level that it would choose privately, an identical competing scheme that is left unregulated will be able to capture the whole market. In the model, the privately set interchange fee resulting from competition between identical schemes leads to a fee structure which maximizes the joint surplus to cardholders and merchants of using cards. When one of the schemes is forced to set a lower merchant fee and higher cardholder fees, users will jointly prefer to switch to the unregulated card scheme.

The analysis highlights the flaw in the logic that just because the regulation of lower interchange fees will cause merchant fees to decrease, proprietary schemes will be forced to also decrease their merchant fees by similar amounts. This logic is based on treating the card schemes as providing a service only to merchants. It ignores the fact that the card schemes also provide a service to cardholders, and that the demand by cardholders and merchants is interdependent. A decrease in interchange fees will lead to an increase in card fees at the same time as it leads to a decrease in merchant fees. Moreover, any reduction in consumers' demand to use cards will effect the value merchants obtain from accepting cards. The overall effect of the regulation of interchange fees may reduce the demand for the regulated card associations. In this case, proprietary schemes will enjoy an increase in demand at the expense of card associations.

Notice this situation is quite different from standard price regulation that imposes a cap on firms' retail prices. Lower retail prices will make the regulated firms more popular with users, not less. In such a scenario, rival unregulated firms will have to match the price reductions to avoid losing business to the regulated firms. This would not constitute a failure of competitive neutrality. The difference here is that an interchange fee is not a retail price set by the card association but rather an instrument that the card association can use to influence the structure of retail prices between those charged to cardholders and those charged to merchants. Competition will not force proprietary schemes to match a suboptimal fee structure imposed on card associations through regulation.

\section{$5 \quad$ Some general lessons}

This paper has addressed some common errors that arise from applying conventional wisdom to two-sided markets. The potential importance of these errors for policy was illustrated by the statements of government authorities in Australia and the United Kingdom with respect to card payment schemes.

Some general lessons for other two-sided markets follow. First, the paper highlights the importance of taking into account both sides of the market (and the interdependence between both sides of the market) in any analysis of two-sided markets. For instance, when analyzing mergers in the magazine and newspaper industry, it would make little sense to consider the impact of the merger only on circulation prices and subscription rates, ignoring the implications for advertising rates as was done in a recent investigation in Germany. ${ }^{34}$ Similarly, it would be wrong to conclude a magazine has (harmful) market power by focusing solely on its price-cost margin on the advertising side.

\footnotetext{
${ }^{34}$ I thank Ulrich Kaiser for bringing this case to my attention. The two publishing houses in Berlin which wanted to merge were Holtzbrinck (publishes "Tagesspiegel") and Berliner Verlag (publishes "Berliner
} 
Second, the paper emphasizes the importance of the structure of prices between the two sides of the market as a strategic instrument, in addition to the overall level of prices. Understanding how this instrument can be used to maximize the joint benefits to both types of customers is critical to determining efficient prices in a two-sided market. The results may be very different from the normal marginal cost pricing familiar in one-sided markets. It should thus not be surprising that relative prices do not reflect relative costs in almost all two-sided markets. Otherwise, shopping malls would charge consumers for entry, Adobe Acrobat would charge the same for Adobe Reader as Adobe Writer, academics would pay hefty fees when submitting their articles to journals, buyers and sellers would pay the same amount in auctions and trading posts, and users would pay to search the Internet.

A number of interesting questions remain to be analysed in the antitrust of two-sided markets. For instance, might the ability to define separate markets (and market power) on each side of a two-sided market depend on whether platforms charge membership fees or just transaction fees? With pure transaction fees, platforms collect revenues from both sides simultaneously whenever there is a transaction, in which case it would seem to make little sense to define separate markets. For instance, it would not make sense to talk of a stand alone rental agency that controlled the market for tenants, but in which there was strong competition among rental agencies for landlords. The antitrust analysis of two-sided markets also needs to take into account the fact that in many cases one side of a two-sided market is not charged anything. Just because consumers are not charged to read Yellow Pages, does not mean one can analyse the market for Yellow Pages advertising without also considering the interrelationship with the consumer side (for instance, the cost of attracting consumers).

It would also be interesting to investigate whether there are new efficiency justifications that arise from exclusive contracts or tying arrangements that platforms may use on one side of the market. Two-sided markets may even have interesting implications for the analysis of price-fixing cases. It is often easier to fix prices on one-sided of the market than the other. This could reflect the fact prices on one side of the market are publicly observable but are not on the other (console versus developer charges for video game platforms). In such case, the result of fixing the price on one side of the market may be just to lead to greater competition on the other side of the market, thereby distorting prices rather than raising the overall level of prices, and potentially eliminating the incentives of the platforms to engage in collusion in the first place.

A final point worth emphasizing about two-sided markets is that there is no obvious reason to expect competition to lead to a more efficient structure of prices than would be set by a monopoly platform. In this respect, the choice of price structure is a bit like the choice of product quality by a monopolist. While clearly a monopolist has an incentive to reduce its quantity so as to raise prices, economic theory tells us that a monopolist may choose an insufficient or an excessive level of product quality. Whether a monopolist selects too much or too little quality rests on differences in the effects of increased quality on the marginal versus the average consumer. The monopolist considers the effect of increased quality on the marginal consumer while the social planner considers the effect of increased quality on the average consumer. This same kind of concern is likely to apply to

Zeitung”). The German monopoly commission only discusses the implications for newspaper sales and editorial independence. See http://www.monopolkommission.de/sg_38/text_s38.pdf 
the choice of price structure in two-sided markets, suggesting any market failure in the structure of prices is likely to be quite subtle.

\section{$6 \quad$ References}

Armstrong, Mark (2002a) "Competition in Two-Sided Markets," Nuffield College, Oxford University, Working Paper.

Armstrong, M. (2002b) "The theory of access pricing and interconnection," in M. Cave, S. Majumdar, and I. Vogelsang (eds.), Handbook of Telecommunications Economics, NorthHolland.

Baxter, William (1983). "Bank Interchange of Transactional Paper: Legal Perspectives," Journal of Law and Economics, 26: 541-588.

Caillaud, Bernard and Bruno Jullien (2003) "Chicken \& Egg: Competition Among Intermediation Service Providers," RAND Journal of Economics, 34: 309-328.

Chakravorti, Sujit (2003) "Theory of Credit Card Networks: A Survey of the Literature," Review of Network Economics, 2: 50-68.

Chakravorti,Sujit and Alpha Shah (2003). "Underlying Incentives in Credit Card Networks," The Antitrust Bulletin, forthcoming.

Chang, Howard and David Evans (2000) "The Competitive Effects of the Collective Setting of Interchange Fees by Payment Card Systems," The Antitrust Bulletin, 45: 641677.

Evans, David (2003a) "The Antitrust Economics of Multi-Sided Platform Markets," Yale Journal on Regulation, forthcoming.

Evans, David (2003b) "Some Empirical Aspects of Multi-sided Platform Industries," Review of Network Economics, 2: 1-20.

Evans, David and Richard Schmalensee (1999) Paying with Plastic: The Digital Revolution in Buying and Borrowing, Cambridge, MA: MIT Press.

Faulhaber, Gerald (1975) "Cross-Subsidization: Pricing in Public Enterprises," American Economic Review, 65: 966-977.

Guthrie, Guthrie and Julian Wright (2003). "Competing Payment Schemes," Working Paper No. 245. Department of Economics. University of Auckland.

Hunt, Robert. (2003) "An Introduction to the Economics of Payment Card Networks," Review of Network Economics, 2: 80-96.

Katz, Michael (2001) "Reform of Credit Card Schemes in Australia II: Commissioned Report," RBA Public Document, August. 
Rochet, Jean-Charles and Jean Tirole (2002). "Cooperation among Competitors: Some Economics of Payment Card Associations," RAND Journal of Economics, 33: 549-570.

Rochet, Jean-Charles. and Jean Tirole (2003a) "Platform Competition in Two-Sided Markets," Journal of the European Economics Association, 1: 990-1029.

Rochet, Jean-Charles. and Jean Tirole (2003b) "An Economic Analysis of the Determination of Interchange Fees in Payment Card Systems," Review of Network Economics, 2: 69-79.

Rochet, Jean-Charles and Jean Tirole (2004) “Defining Two-Sided Markets," mimeo, IDEI and GREMAQ, Toulouse.

Roth, Alex (2003) "Kiss Ladies Night Goodbye," The San Diego Union Tribute, August 3. http://www.signonsandiego.com/news/metro/20030803-9999_1m3ladies.html.

Schmalensee, Richard (2002) "Payment Systems and Interchange Fees," Journal of Industrial Economics, 50: 103-122.

Schwartz, Marius and Daniel Vincent (2001) "Same Price, Cash or Credit: Vertical Control in Electronic Payments Networks," mimeo, November.

Small, John and Julian Wright (2001) "The Bilateral Negotiation of Interchange Fees in Payment Schemes," mimeo, NECG and University of Auckland.

Wright, Julian (2002) "Access pricing under competition: An application to cellular networks," Journal of Industrial Economics, L: 289 - 315.

Wright, Julian (2003a) "Pricing in Debit and Credit Card Schemes," Economics Letters, 80: 305-309.

Wright, Julian (2003b) “Optimal Card Payment Systems," European Economic Review, 47: 587-612.

Wright, Julian (2004) "Determinants of Optimal Interchange Fees in Payment Systems," Journal of Industrial Economics, Vol LII. No. 1. 